\title{
Author Correction: Balancing efficient analysis and storage of quantitative genomics data with the D4 format and d4tools
}

Hao Hou, Brent Pedersen and Aaron Quinlan (D)

Correction to: Nature Computational Science https://doi.org/10.1038/s43588-021-00085-0, published online 21 June 2021.

In the version of this article initially published, there was an error in the caption of Fig. 2. Specifically, in the last sentence, now reading in part, "If, however, an entry does exist, as in the cases of coordinate 1,000,011," coordinate 1,000,011 initially appeared as "1,000,010."

The change has been made to the HTML and PDF versions of the article.

Published online: 15 February 2022

https://doi.org/10.1038/s43588-022-00211-6

(c) The Author(s), under exclusive licence to Springer Nature America, Inc. 2022 